\title{
Immunoglobulins in the jejunal mucosa in adult coeliac disease and dermatitis herpetiformis after the reintroduction of dietary gluten
}

\author{
M. LANCASTER-SMITH', SUSAN JOYCE, AND PARVEEN KUMAR \\ From the Department of Gastroenterology, St. Bartholomew's Hospital, London
}

SUMmary Cells containing immunoglobulin (IgA, IgG, IgM) have been measured and the distribution of extracellular and epithelial cell immunoglobulin assessed in treated patients with adult coeliac disease (ACD) and dermatitis herpetiformis $(\mathrm{DH})$ before and after gluten was reintroduced to the diet. Patients with ACD and DH frequently had IgM and IgG cells above the normal range even before re-exposure to gluten, although the range of IgA cells was normal. In both diseases IgA and IgM cells increased after gluten with a proportionally greater rise in the latter, so that numbers of IgM cells, but not of IgA, exceeded the control range in all but one patient. There were increased quantities of IgA and IgM extracellularly in the lamina propria and in epithelial cells after challenge with gluten. Third component of complement was also found in some biopsies after re-exposure to gluten. These findings support the suggestion that gluten induces a humoral immunological response within the small intestinal mucosa and that both IgA and IgM systems are involved.

Although gluten is known to cause the small intestinal lesion of both coeliac disease (CD) and dermatitis herpetiformis (DH), the mechanisms involved in its pathogenesis remain unknown. However, the increased numbers and abnormal predominance of IgM over IgA containing cells in the jejunal mucosa of patients with ACD (Crabbé and Heremans, 1966; Douglas et al., 1970; Soltoft, 1970; Pettingale, 1971; Savilahti, 1972; Lancaster-Smith et al., 1974) suggest that humoral immune mechanisms may be involved. Additional evidence for this is provided by the ultrastructural changes (Shiner, 1973) and deposition of immunoglobulins in the small intestinal mucosa of treated patients (Shiner and Ballard, 1972; Doe et al., 1974) after gluten challenge. Furthermore, in vitro studies with coeliac jejunal mucosa have shown an increased synthesis of IgA and IgM after challenge with gluten (Loeb et al., 1971), much of this being antibody against gluten (Falchuk and Strober, 1974). By using immunofluorescent techniques the aim of this investigation was to complement these latter studies and look for

\footnotetext{
'Present address: Gastroenterology Unit, Queen Mary's Hospital, Sidcup, Kent.
}

Received for publication 28 March 1977 further evidence that jejunal immunoglobulin production is stimulated after reintroduction of dietary gluten in treated patients with adult coeliac disease (ACD) and dermatitis herpetiformis (DH).

\section{Methods}

\section{PATIENTS}

The diagnosis of ACD was made on clinical and biochemical evidence of malabsorption, villous atrophy of the jejunum and reversal of these features on a gluten free diet. DH was diagnosed on clinical and histological features of the rash and its response to Dapsone.

\section{ADULT COELIAC DISEASE}

Nine patients who had been on a gluten free diet from one to 15 years (mean 5.5 years) were studied. Before gluten challenges villous heights ranged from 197 to $492 \mu$, mean $339 \mu$ (normal $>330 \mu$ ) and surface cell heights from 21-34 $\mu$, mean 29 (normal $>29 \mu)$.

DERMATITIS HERPETIFORMIS

Nine patients, six of whom had a previous significant jejunal lesion were studied. These six had been on a 
gluten free diet from five to 24 months (mean 18 months). Before gluten challenges they had villous heights ranging from 290-517 $\mu$ (mean $389 \mu$ ) and surface cell heights from 27-30 $\mu$ (mean $29 \mu$ ). The three remaining patients had never been on a gluten free diet and had normal jejunal morphology, with villous heights ranging from 405 to $517 \mu$, and surface cell heights from 30 to $34 \mu$.

\section{CONTROLS}

Jejunal biopsies were obtained from nine patients who were undergoing investigation for gastrointestinal symptoms, all of whom had normal morphology of the small bowel, and no evidence of immunological disorders.

\section{Methods}

Gluten challenges were of three types:

1. Nine patients (six with ACD and three with DH) had jejunal biopsies while on gluten free diets and again after seven days on a diet containing between 10 and $20 \mathrm{~g}$ gluten per day in the form of normal dietary constituents.

2. Eight patients (four with ACD and four with DH) on gluten free diets were submitted to biopsy before and at 24 to 48 hours after a single $25 \mathrm{~g}$ dose of gluten.

3. The three DH patients who had normal jejunal morphology on diets containing 10-20 g gluten per day were submitted to biopsy again between one to three weeks after taking $\mathbf{4 0} \mathrm{g}$ of extra gluten per day as a single measured amount.

Biopsies were taken in all instances by a Crosby capsule in fasting subjects from the duodenojejunal junction. The tissue was divided. One piece was processed for routine histology from which $5 \mu$ thick sections were prepared. Surface cell and villous heights were measured (Stewart et al., 1967) and intraepithelial lymphocytes were counted (Ferguson and Murray, 1971). Paired sections adequate for comparison of these measurements in pre- and postchallenge biopsies were available from 12 patients (nine with $\mathrm{ACD}$, three with $\mathrm{DH}$ ). The remaining tissue was prepared for immunofluorescent microscopy (Lancaster-Smith et al., 1974). Sections $6 \mu$ thick were prepared and stained with antisera to human IgA, IgG, IgM, and third component of complement conjugated with fluorescein isothiocyanate (Behringwerke). The numbers of immunofluorescent cells of each immunoglobulin class were estimated using a direct counting technique (Savilahti, 1972) over an area $0.5 \mathrm{~mm}^{2}$ between the epithelium and muscularis mucosae. In the majority of biopsies the presence and degree of extracellular and epithelial cell staining were also recorded (Shiner and Ballard, 1972). All observations were made without prior knowledge of whether the section was from a pre- or post-challenge biopsy.

Results (Tables 1-3)

IgA CELLS

Patients with ACD and DH on a gluten free diet had the same numbers of IgA cells. In both conditions IgA containing cells tended to be fewer than in control subjects and in those with coeliac disease the difference was just significant $(P<0.05)$. In the eight patients studied after a single $25 \mathrm{~g}$ gluten challenge at 24 to 48 hours there was a modest increase of IgA cells in all four patients with ACD and in three of four patients with DH. In the nine patients (six ACD, three DH) studied after seven days on a gluten containing diet there was an increase in IgA cells compared with pre-gluten levels $(P<0.05)$. Despite this increase after challenge, the numbers of $\operatorname{IgA}$ cells in

Table 1 Immunoglobulin containing cells (mean $\pm S E$ ) in adult coeliac disease and dermatitis herpetiformis before and 24-48 hours after a single $25 \mathrm{~g}$ gluten challenege

\begin{tabular}{lllllll}
\hline & & No. & \multicolumn{1}{l}{$I g A$} & \multicolumn{1}{l}{$I g G$} & \multicolumn{1}{l}{$I g M$} & \multicolumn{2}{l}{ Total } \\
\hline ACD & Pre & 4 & $605 \pm 33$ & $95 \pm 15$ & $285 \pm 32$ & $985 \pm 53$ \\
& Post & 4 & $875 \pm 95$ & $110 \pm 17$ & $340 \pm 37$ & $1325 \pm 134$ \\
DH & Pre & 4 & $685 \pm 66$ & $85 \pm 15$ & $225 \pm 22$ & $995 \pm 52$ \\
& Post & 4 & $725 \pm 50$ & $135 \pm 31$ & $330 \pm 24$ & $1190 \pm 44$ \\
& & 9 & $744 \pm 50$ & $49 \pm 8$ & $189 \pm 11$ & $982 \pm 56$ \\
\hline
\end{tabular}

Key to Tables 1-3: DH: Dermatitis herpetiformis. ACD: Adult coeliac disease. Cell expressed as numbers per $\mathrm{mm}^{2}$.

Table 2 Immunoglobulin containing cells (means $\pm S E$ ) in adult coeliac disease and dermatitis herpetiformis before and after seven days on a gluten-containing diet

\begin{tabular}{|c|c|c|c|c|c|c|c|}
\hline & & No. & $I g A$ & & $I g G$ & $I g M$ & Total \\
\hline ACD & $\begin{array}{l}\text { Pre } \\
\text { Post }\end{array}$ & $\begin{array}{l}6 \\
6\end{array}$ & $\begin{array}{l}620 \pm \\
850 \pm\end{array}$ & $\begin{array}{c}30 \\
1031\end{array}$ & $\begin{array}{r}87 \\
113\end{array}$ & $\begin{array}{l}256 \pm 43 \\
336 \pm 26\end{array}$ & $\begin{array}{r}963 \pm 61 \\
1300 \pm 119\end{array}$ \\
\hline DH & $\begin{array}{l}\text { Pre } \\
\text { Post }\end{array}$ & $\begin{array}{l}3 \\
3\end{array}$ & $\begin{array}{l}680 \pm \\
860 \pm\end{array}$ & $\begin{array}{l}61 \\
66\end{array}$ & $\begin{array}{l}87 \pm 18 \\
87 \pm 24\end{array}$ & $\begin{array}{l}213 \pm 18 \\
313 \pm 37\end{array}$ & $\begin{array}{r}980 \pm 31 \\
1166 \pm 24\end{array}$ \\
\hline \multicolumn{2}{|c|}{ Controls } & 9 & $744 \pm$ & 50 & $49 \pm 8$ & $189 \pm 11$ & $982 \pm 56$ \\
\hline
\end{tabular}

Table 3 Immunoglobulin containing cells (means $\pm S E$ ) in $D H$ patients with normal mucosa on normal diets before and after extra gluten.

\begin{tabular}{llclll}
\hline & & IgA & IgG & IgM & \multicolumn{1}{l}{ Total } \\
\hline Normal diet & 3 & $680 \pm 10667 \pm 18$ & $190 \pm 17$ & $937 \pm 107$ \\
Extra gluten & 3 & $826 \pm 6773 \pm 13$ & $206 \pm 7$ & $1106 \pm 77$ \\
\hline
\end{tabular}


post-challenge biopsies did not differ from those in the controls.

\section{IgG CELLS}

Patients with ACD and DH on a gluten free diet had the same numbers of IgG cells and in both groups of patients these were significantly greater than in controls $(P<0.05 ; P<0.05)$. There was no significant change in IgG cells compared with prechallenge numbers in the patients studied after either a single $25 \mathrm{~g}$ challenge or seven days on a diet containing gluten. However, the numbers of IgG cells exceeded control values after both the single dose gluten challenge $(P<0.01)$ and seven days on a diet containing gluten $(\mathrm{P}<0.05)$.

I gM CELLS

Patients with ACD and DH on a gluten free diet had the same numbers of IgM cells and in both diseases these were greater than controls $(\mathrm{P}<0.05 ; \mathrm{P}<$ 0.05 ). In the eight patients (four ACD, four $D H$ ) studied at 24 to 48 hours after a single $25 \mathrm{~g}$ challenge, IgM cells increased compared with pre-challenge levels $(P<0.01)$. In the nine patients (six ACD, three $\mathrm{DH}$ ) studied after seven days on a gluten containing diet there was an increase in IgM cells compared with pre-gluten levels $(\mathrm{P}<0.01)$. In contrast with IgA, the number of cells containing IgM was markedly higher than in controls after both the single dose $(P<0.002)$ and seven day $(P<0.002)$ challenges.

TOTAL IMMUNOFLUORESCENT CELLS

$(\mathrm{IgA}+\mathrm{IgM}+\mathrm{IgG})$

Patients with ACD and DH on a gluten free diet had the same numbers of immunofluorescent cells as controls. Both after a single $25 \mathrm{~g}$ challenge and after seven days on a gluten containing diet there was an increase in these cells compared with pre-challenge levels $(P<0.01 ; P<0.01)$. Total immunofluorescent cells exceeded control values after both the single $25 \mathrm{~g}$ gluten challenge $(\mathrm{P}<0.05)$ and seven days on a gluten containing diet $(P<0.05)$.

The three patients with DH without jejunal lesions on normal diets had the same numbers of all three classes of immunoglobulin containing cells as controls. IgA cells tended to increase after ingestion of extra gluten but the numbers studied were insufficient for statistical analysis.

After gluten challenge the increase in IgM cells correlated with the decrease in villous heights when both changes were expressed as a percentage of prechallenge levels $(P<0.01)$ (Figure). There was no correlation between reduction of villous heights and changes in IgA or IgG cells or between any immuno- globulin class and changes in surface cell heights or intraepithelial lymphocyte counts.

EXTRACELLULAR IMMUNOGLOBULINS IN

LAMINA PROPRIA

The distribution of extracellular immunoglobulins in the lamina propria was the same in ACD and DH. Lamina propria $\operatorname{IgA}$, when present, occurred most frequently and at the greatest intensity in the region of the epithelial cell basement membrane. It was found in only five of 13 biopsies before gluten challenge but in all seven after a single dose of gluten and in five of six after seven days on a gluten containing diet. IgA basement membrane staining of low intensity was also present in two of nine controls. Extracellular IgM was present in five of seven biopsies at 24 to 48 hours after a single dose of gluten. The intensity was almost always less than for IgA but had the same distribution along the basement membrane. There was no detectable extracellular IgM in controls or in biopsies before gluten challenge or after seven days on a gluten containing diet. Anti $C_{3}$ serum gave rise to faint patchy staining around blood vessels. This was found only at 24 to 48 hours in six of seven patients after a single dose challenge but, as with IgM, not in other biopsies from patients or controls.

Unlike IgA and IgM, IgG antiserum gave rise to diffuse staining of the lamina propria that was not confined to the basement membrane region. There was no detectable difference between pre- and postchallenge specimens or controls.

EPITHELIAL CELL IMMUNOGLOBULINS

The apical portions of epithelial cells, especially those in the crypts and bases of villi, stained clearly for IgA in eight of nine controls, 10 of 13 prechallenge and all 13 post-challenge biopsies. It was usually most intense in this last group. Staining of epithelial cells for IgM was less common and intensity lower than for IgA. It was present in only three of nine controls, six of 13 pre-challenge biopsies, and in all but one of the 13 post-challenge specimens. As with IgA, the greatest intensity occurred in postchallenge biopsies. No IgG or third component was detected in epithelial cells.

\section{Discussion}

That the IgM system is involved in the pathogenesis of the small bowel lesion of ACD and DH is suggested by the rise in IgM cells after re-exposure to gluten. Furthermore, in both the present and other studies IgM cells remain raised despite gluten withdrawal in many patients with ACD (Douglas et al., 1970; Soltoft, 1970; Brandtzaeg and Baklien, 1976) 


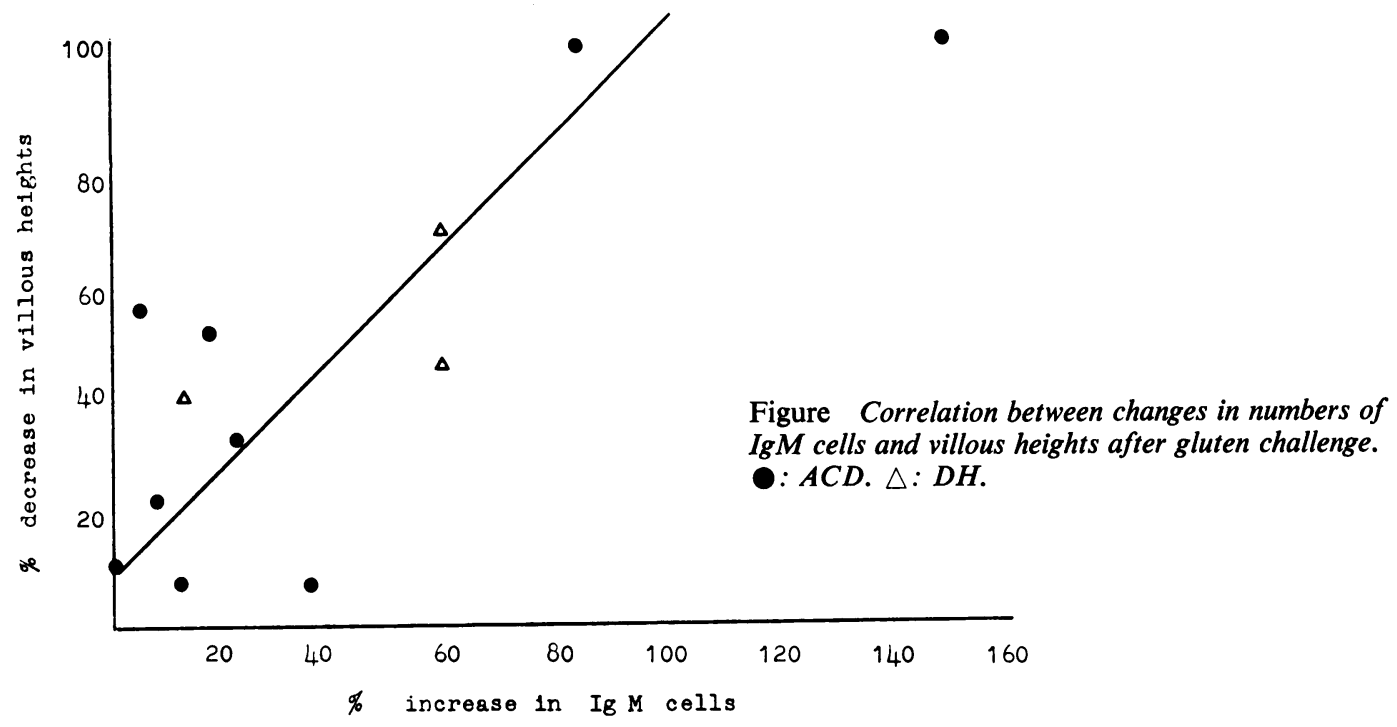

and DH (Lancaster-Smith et al., 1974). It seems possible that these raised counts may be caused by the continued ingestion of small amounts of gluten. If this is the explanation for the IgM cell excess, which occurs in the presence of normal or low IgA cell counts, it would imply that the IgM system is the more sensitive to small amounts of gluten and that it may possibly be related to the frequent failure of the jejunal morphology to return completely to normal in adult patients (Holmes et al., 1974). Additional evidence for the involvement of IgM in the pathogenesis of the jejunal lesion is the correlation between the rise in IgM cells and reduction in villous heights which was not apparent for other immunoglobulin classes. This and the presence of extracellular lamina propria IgM in the early stages after gluten challenge, but not in the pre-challenge or control biopsies, might suggest that this immunoglobulin is perhaps more closely associated with the immunological reaction to gluten per se than the other classes.

In this same group complement was also detected, albeit in small quantities and only around blood vessels. The relevance of this is not clear, but complement and IgM have been demonstrated along the basement membrane at a similar interval after gluten by Doe and his colleagues (1974). They suggest this is an indication of immune complex deposition, but it might merely represent increased release of these substances into the lamina propria, after the stimulation of gluten challenge. Nevertheless, the increase at this time of lamina propria eosinophils (LancasterSmith, 1975) which are attracted by immune com- plexes (Kay, 1970) would support Doe's suggestion. Subsequent clearing of such complexes by these and other phagocytic cells might also explain why this pattern of staining was not seen in adult patients studied after more than 48 hours and in children after prolonged re-exposure to gluten (LancasterSmith et al., 1976).

This study shows that the jejunal IgA cell population also increases after even a brief challenge with gluten and, as for the other classes of immunoglobulin, the rises are comparable with those found in children after a more prolonged re-exposure (Lancaster-Smith et al., 1976). The only major difference is that, unlike the situation in childhood disease, adult IgA cell numbers, after challenge, do not exceed the normal range. This is almost certainly caused by the relatively low pre-challenge levels in the adults rather than the length of the re-exposure, as even untreated adult patients on long-standing gluten containing diets usually have low (Douglas $e t$ al., 1970; Pettingale, 1971) or normal (Soltoft, 1970; Lancaster-Smith et al., 1974) densities of IgA cells. Further evidence that gluten stimulates jejunal IgA production and secretion is the increase in epithelial cell and extracellular IgA in both adults and children (Shiner and Ballard, 1972; Lancaster-Smith et al., 1976) after widely varying types of challenge.

The tendency for IgG cells to rise after gluten challenge in adults and children (Lancaster-Smith $e t$ al., 1976) and the increased numbers frequently found in ACD and DH, especially in untreated patients (Soltoft, 1970; Savilahti, 1972; LancasterSmith, 1974; Brantdzaeg and Baklien, 1976) suggest 
that it may also play a part in the intestinal response to gluten and other antigens.

Comparison of these results with those from children studied three months after gluten was reintroduced (Lancaster-Smith et al., 1976) suggests that, after a rapid initial rise, the numbers of cells containing detectable immunoglobulins of all three classes remain fairly constant, despite the continuing presence of gluten.

Our findings are complementary to the in vitro studies of Loeb et al. (1971), who demonstrated increased synthesis of both IgA and IgM after reexposure of coeliac jejunal mucosa to gluten. Much of this IgA and IgM has antigliadin activity (Falchuk et al., 1974) and it is probable, therefore, that at least some of the increase in jejunal IgM and IgA seen in our patients represents production of antibodies to gluten.

Although there is no conclusive evidence that the bowel lesion of ACD and DH is caused by a primary disorder of immunity, humoral immunological phenomena rapidly take place in the jejunum after contact with gluten, and it seems likely that they play some part in the development of the intestinal lesion. However, the generally less severe reduction of villous heights despite gross comparable quantitative immunological changes after gluten challenge and the milder jejunal abnormality usually seen in DH compared with ACD imply that other factors also control the severity of the intestinal lesion.

\section{References}

Brandtzaeg, P., and Baklien, K. (1976). Immunohistochemical studies of the formation and epithelial transport of immunoglobulins in normal and diseased human intestinal mucosa. Scandinavian Journal of Gastroenterology, 11, suppl. 36.

Crabbé, P. A., and Heremans, J. F. (1966). Lack of gamma A. immunoglobulin in serum of patients with steatorrhoea. Gut, 7, 119-127.

Doe, W. F., Henry, K., and Booth, C. C. (1974). Complement in coeliac disease. In Coeliac Disease: Proceedings of the 2nd International Coeliac Symposium, pp. 189-196. Edited by W. Hekkens and A. S. Peña. Stenfert Kroesse: Leiden. Douglas, A. P., Crabbé, P. A., and Hobbs, J. R. (1970). Immunochemical studies of the serum, intestinal secretions and intestinal mucosa in patients with adult celiac disease and other forms of celiac syndrome. Gastroenterology, 59, 414-425.

Falchuk, Z. M., and Strober, W. (1974). Gluten sensitive enteropathy. Synthesis of antigliadin antibody in vitro. Gut, 15, 947-952.

Ferguson, A., and Murray, D. (1971). Quantitation of intraepithelial lymphocytes in human jejunum. Gut, 12, 988-994.

Holmes, G. K. T., Asquith, P., Stokes, P. L., and Cooke, W. T. (1974). Cellular infiltrate of jejunal biopsies in adult coeliac disease in relation to gluten withdrawal. Gut, 15, 278-283.

Kay, A. B. (1970). Studies on eosinophil leucocyte migration. Clinical Experimental Immunology, 7, 723-737.

Lancaster-Smith, M., Kumar, P. J., and Dawson, A. M. (1975). The cellular infiltrate of the jejunum in adult coeliac disease and dermatitis herpetiformis following the reintroduction of dietary gluten. Gut, 16, 683-688.

Lancaster-Smith, M., Kumar, P., Marks, R., Clark, M. L., and Dawson, A. M. (1974). Jejunal mucosal immunoglobulin-containing cells and jejunal fluid immunoglobulins in adult coeliac disease and dermatitis herpetiformis. Gut, 15, 371-376.

Loeb, P. M., Strober, W., Falchuk Z., M., and Laster, L. (1971). Incorporation of L-leucine-1" $\mathrm{C}$ into immunoglobulins by jejunal biopsies of patients with celiac sprue and other gastrointestinal diseases. Journal of Clinical Investigation, 50, 559-569.

Pettingale, K. W. (1971). Immunoglobulin-containing cells in the coeliac syndrome. Gut, 12, 291-296.

Savilahti, E. (1972). Intestinal immunoglobulins in children with coeliac disease. Gut, 13, 958-964.

Shiner, M. (1973). Ultrastructural changes suggestive of immune reactions in the jejunal mucosa of coeliac children following gluten challenge. Gut, 14, 1-12.

Shiner, M., and Ballard, J. (1972). Antigen-antibody reactions in jejunal mucosa in childhood coeliac disease after gluten challenge. Lancet, 1, 1202-1205.

Søltoft, J. (1970). Immunoglobulin containing cells in nontropical sprue. Clinical and Experimental Immunology, 6, 413-420.

Stewart, J. S., Pollock, D. J., Hoffbrand, A. V., Mollin, D. L., and Booth, C. C. (1967). Study of proximal and distal intestinal structure and absorptive function in idiopathic steatorrhoea. Quarterly Journal of Medicine, 36, 425-444. 